\title{
Some medicolegal aspects of the management of acute head injury
}

\author{
BRYAN JENNETT \\ British Medical fournal, 1976, 1, 1383-1385
}

There are some relatively common circumstances in which doctors claim to do more in the way of management than they believe to be necessary on medical grounds. Not only may this put their patients to inconvenience and even risk but it represents a mistaken use of resources. One such condition is acute head injury. It is often asserted that numerous unnecessary skull $x$-ray cases of head injury reported to them over five years; a few of these are usually said to be done for medicolegal reasons, which are also held responsible for many of the large numbers of patients admitted to hospital after mild injury. It seemed of some interest to discover the actual circumstances in cases of head injury that had come to the notice of the medicolegal organisations in recent years. In the event most of these cases proved to be remarkably similar, and this seemed worth reporting.

\section{Source of data}

The Medical Defence Union and the Medical Protection Society kindly agreed to make available answers to a set of questions about all cases of head injury reported to them over five years; a few of these were from Australasia. Confidentiality of the records precluded my scrutinising them myself, but these two bodies were most helpful in providing as much data as possible within these limits. The Medical Defence Union traced many more patients (52) than the Medical Protection Society ( 8 ) because their filing system allowed the cases to be retrieved by diagnosis. Of these 60 cases five were excluded because head injury was judged to have formed only a minor part of the problem or because the incident had arisen out of some mishap in

University Department of Neurosurgery, Institute of Neurological Sciences, Glasgow G51 4TF

BRYAN JENNETT, MD, FRCS, professor of neurosurgery hospital-for example, falling out of bed. This left 55 cases of which two were of chronic subdural haematoma in which general practitioners were said to have been slow to diagnose and initiate appropriate referral. The analysis was restricted to the 53 cases of head injury in which the patient had presented soon after injury for medical care.

By no means all these cases were pursued as cases of negligence; some were reported because of comments arising in the Coroner's Court or newspapers, which led a doctor to inform his defence society as a precaution. It is no part of this investigation to consider the justification of the allegations of negligence or the legal outcome of the cases. My intention was simply to find out the aspects of management that had prompted questions to be asked.

\section{Findings}

Deterioration after mild injury-Most cases were of patients judged initially to have been only mildly injured but who subsequently developed serious complications, which were often fatal. No less than $49(92 \%)$ had talked at some stage after the injury, yet $36(68 \%)$ died. Altogether $46(87 \%)$ of the series died. It is not surprising that in such circumstances relatives might consider that the patient's death could have been prevented. An acute intracranial haematoma was the cause of death in $29(81 \%)$ of the 36 who had talked and occurred in 30 $(57 \%)$ of the whole series; two-thirds of the haematomas were intradural.

Admission to hospital-Twenty-six patients had not been admitted to hospital immediately after injury: 21 were sent home from the casualty department, and the remaining five were seen initially by a general practitioner who did not immediately refer them to hospital. All of these patients subsequently returned to hospital, having deteriorated. Sixteen patients were admitted initially to hospital because of head injury but deteriorated and died; complications developed in 12 patients while they were still under observation in hospital, but in the remaining four complications occurred after they had been discharged, usually $24-48$ hours after injury.

Skull $x$-ray examination - The question of failure to take, interpret, or communicate the results of skull $x$-ray films was a feature of 30 $(63 \%)$ of the hospital cases (16 not taken, nine fractures missed, and five delayed reports). In every one of the 21 patients sent home from hospital there was some irregularity about the skull $x$-ray picture. 
Other features-No less than $21(40 \%)$ patients were reported as being under the influence of alcohol when the injury was sustained; six of these were in police custody, usually after having been seen at hospital. In several cases head injury occurred in the context of multiple injury or of other medical disease-for example, stroke-and questions had arisen because the head injury had either been overlooked or its recognition delayed. In some of these cases failure to diagnose the head injury was probably not crucial to the outcome.

\section{Comment}

Most of the cases coming to the notice of the Medical Defence Union and the Medical Protection Society were of injuries that had at first seemed to be mild, often in patients who were drunk; but the patients then deteriorated and died, usually due to an intracranial haematoma.

\section{PATIENTS WHO TALK AND LATER DIE}

A recent study reported that more than a third of patients with fatal head injuries in a neurosurgical unit had talked at some time after injury; a similar proportion of those surviving head injuries who were in coma for some time had also had a lucid interval. ${ }^{6}$ In patients who had been lucid an intracranial haematoma was found in three-quarters of those who died and in two-thirds of the survivors after coma. The causes of death in patients without a haematoma who came to necropsy were raised intracranial pressure due to brain swelling, usually associated with contusions; hypoxic-ischaemic damage, sometimes after status epilepticus; or meningitis.

\section{DIAGNOSIS OF HAEMATOMA}

When a lucid patient lapses into coma a few hours after injury with one fixed dilated pupil an intracranial haematoma is soon suspected and is usually confirmed at operation. But this classical syndrome is the exception rather than the rule. In one recent series a third of the patients with traumatic haematomas reaching a neurosurgical unit had already been deteriorating for more than 12 hours in another hospital. ${ }^{7}$ The commonest causes of delay were mistaken diagnoses of cerebrovascular accident or drunkenness. An unsuspected intracranial haematoma is often discovered at necropsy. ${ }^{7} 8$ Almost $80 \%$ of adults with intracranial haematomas have a fracture, ${ }^{79}$ and when a patient who is thought to be drunk, or to have had a stroke, is found to have a fracture then a traumatic haematoma should always be suspected and will usually be found.

\section{SIGNIFICANCE OF SKULL FRACTURE AND VALUE OF SKULL X-RAY} FILMS

The significance of a skull fracture and value of an $x$-ray film are clearly connected; only if it is significant to find a fracture is it important to obtain an $x$-ray picture of the skull. Opinions on both these questions are sharply divided, as is often evident from the correspondence columns of the journals. Radiologists ${ }^{13-5}$ tend to emphasise that management is seldom influenced by knowledge that a skull fracture exists; they also stress that good films are difficult to obtain soon after injury and often conclude that skull $x$-ray pictures taken in accident departments are either unnecessary or useless, or both. Neurosurgeons, ${ }^{2}$ who inevitably encounter patients who have developed complications, tend to emphasise the importance of knowing about a skull fracture. They emphasise that intracranial haemorrhage or infection can develop after injuries that appear initially to have been mild but that they rarely occur without a fracture. Intracranial haematomas are often undiagnosed, at least for a time, because the presence of a fracture is unsuspected or ignored. Intracranial infection not only frequently results when a compound depressed fracture is overlooked but it may result in death or persisting disability. ${ }^{10}$ Failure to suspect a depressed fracture is usually due to the fact that the patient was never (or only briefly) unconscious after the accident, and consequently did not undergo $x$-ray examination. To maximise the chances of predicting and perhaps preventing these dangerous complications the neurosurgeon regards skull $x$-ray examination as an essential part of the early management of the patient with a head injury. In effect, every scalp laceration has to be regarded as possibly overlying a depressed fracture and every orbital or retromastoid haematoma as possibly indicative of a fractured base.

It is often implied that many skull $x$-ray pictures are taken because of medicolegal considerations rather than clinical necessity. ${ }^{4}$ The defence societies sometimes enter the correspondence columns with a reminder that they do indeed have to defend doctors in accident cases in which it is alleged that an $x$-ray picture should have been taken or been more adequately interpreted. ${ }^{11} 12$ Nevertheless, they recommend that $x$-ray pictures should be taken only when the doctor deems it wise to do so in a particular case. In a case successfully defended by the Medical Defence Union, which went to appeal, Lord Denning stated specifically that the courts did not always find that there had been negligence because a patient had not undergone $x$-ray examination (after injury); it depended, he said, on the circumstances of each case. ${ }^{13}$

\section{ADMISSION TO HOSPITAL}

The commonest reason for admission to hospital is some change in consciousness, either immediately after injury or on examination in the accident department. Many of these patients have no fracture. The question often arises about whether the finding of a fracture itself makes it necessary to admit a patient to hospital. In the light of the clinical and pathological evidence that when dangerous complications develop after initially mild injuries there usually is a skull fracture, it seems inescapable that all patients found to have a fracture should be admitted, however well they seem to be clinically and whether or not they have had a brief period of unconsciousness.

Certainly failure to obtain skull $x$-ray films and failure to admit to hospital were common features in the medicolegal cases reported here: often one led to the other. $X$-ray pictures were sometimes taken, however, and not properly interpreted, or patients were admitted and not adequately observed, because several developed fatal complications while still in hospital or after discharge following a period of observation. Neither ritual radiography nor ritual admission will do much to reduce the frequency of preventable death and disability due to the delayed diagnosis of serious intracranial complications after mild injuries. That will come only when there is keener awareness of the clinical features of head injury that point to a risk of complications and to the need for careful observation and perhaps investigation of such patients.

\section{Recommendations and conclusions}

Only a small proportion of those with mild head injuries develop serious complications, yet 140000 patients with mild head injuries are admitted to hospital annually ${ }^{14}$; more than half are discharged in less than 48 hours, and there have been suggestions that some of these patients with milder head injuries could safely be sent home. ${ }^{15-18}$ Already four or five times as many patients with head injuries come to the accident departments of hospital as are admitted. A selective admission policy would require better training for staff in accident departments and the provision of efficient and readily available radiography facilities. It has been pointed out that unnecessary $x$-ray examinations are economically wasteful, ${ }^{19}$ but so is unnecessary admission to hospital.

Recommendations must be realistic in terms of the staff likely 
to be available, both casualty clinicians and radiologists. It is unlikely that there will ever be enough radiologists to staff accident and emergency departments, particularly at the times when head injuries are most common. The onus must continue to fall on casualty clinicians, who need to be more clearly instructed both in the clinical assessment of head injury and in the indications for and the interpretation of skull radiographs. As might be expected they tend to be over-cautious; in one audit false-positive readings of radiographs were twice as common as false-negative readings. ${ }^{20}$ It should be remembered, however, that junior medical staff at present rarely receive any formal instruction in the interpretation of skull $x$-ray films. Head injury is so common and potentially so dangerous that it might be wise to require medical staff in accident departments to participate in some form of self-instruction in how to read skull $x$-ray films; this could be provided by a tape/slide unit. These doctors must not only learn to recognise skull fractures; they also need to know when films are too poor to be a safe basis for diagnosis and be empowered to request repeat films after consultation with the radiographer. It is essential for the safety of patients that clinicians, radiologists, and radiographers should collaborate in solving this difficult problem.

Unless it becomes possible to provide adequate radiological facilities inevitably many patients will be unnecessarily admitted to hospital. Given reasonable radiography it would be appropriate to admit, from those patients fully conscious and without neurological signs, only those who have been shown to have a fracture or in whom a fracture is suspected and cannot, for one reason or another, be excluded.

As resources become more restricted it becomes all the more important to ensure that they are allocated wisely, to benefit as many patients as possible. It is doubtful whether a significant proportion of resources should be deployed to avoid a very occasional event, because this might raise medicolegal questions, particularly if this entails denying treatment of undoubted benefit to many other patients. ${ }^{21}$ None the less, it must be concluded that in most of the cases reviewed here, because they had come under scrutiny for medicolegal reasons, there were clear clinical indications that they should have been more carefully managed. Before legal considerations are blamed for forcing doctors to practice defensive medicine we should remember that lawyers are supposed to judge our actions by what is normal careful practice.

Thanks are due to Dr A L Gwynne and Miss Allatt of the Medical Defence Union and to Dr D Murray of the Medical Protection Society, for extracting the data from their files.

\section{References}

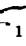

Burkinshaw, J, British Medical fournal, 1972, 1, 378.

2 Clarke, P R R, British Medical fournal, 1972, 1, 570.

${ }^{3}$ Hughes, H P, British Medical fournal, 1974, 3, 41.

4 Connell, M C, British Medical fournal, 1974, 3, 291.

${ }^{5}$ Bell, R S, and Loop, J W, New England fournal of Medicine, 1971, 254, 236.

${ }^{6}$ Reilly, P L, et al, Lancet, 1975, 2, 375.

${ }^{7}$ Galbraith, S, British Medical fournal, in press.

8 James, T G I, and Turner, E A, Lancet, 1951, 2, 45.

${ }^{9}$ Galbraith, S, Lancet, 1976, 1, 501.

${ }^{10}$ Jennett, B, and Miller, J D, fournal of Neurosurgery, 1972, 36, 333.

${ }^{11}$ Taylor, J L, British Medical fournal, 1974, 3, 406.

12 Addison, P H, British Medical fournal, 1971, 2, 278.

${ }^{13}$ Denning, J, Lancet, 1966, 2, 237.

${ }^{14}$ Field, J H, A Study of the Epidemiology of Head Injury in England and Wales. London, Department of Health and Social Security, 1976.

15 Jennett, B, British Medical fournal, 1975, 3, 267.

${ }^{16}$ Lewin, W, The Management of Head Injuries. London, Bailliere, Tindall and Cox, 1966.

${ }^{17}$ Northfield, D W C, The Surgery of the Central Nervous System. Oxford, Blackwell, 1973.

${ }^{18}$ Galbraith, S, Lancet, 1973, 1, 1381.

19 Wernier, M. J, Lancet, 1973, 2, 382.

20 Jennett, B. and Davidson, J A K, unpublished observations.

${ }^{21}$ Norcross, K, Lancet, 1976, 1, 737.

\title{
Problems of Childhood
}

\section{Puberty: precocious and delayed}

\author{
P H W RAYNER
}

British Medical fournal, 1976, 1, 1385-1387

\section{Endocrine control of puberty}

Gonadotrophins and sex hormones are secreted during infancy and childhood, and a feedback system operates between the hypothalamus, the pituitary, and the gonads. It is, however, set at a low level, so that the small amounts of sex hormones secreted by the gonads are enough to inhibit the secretion of hypothalamic releasing hormone and pituitary gonadotrophins. The onset of puberty is triggered by a decreasing sensitivity of the hypothalamus to sex hormones, so that releasing factor and gonadotrophin secretion rises and leads in turn to higher levels

The Children's Hospital, Ladywood, Birmingham B16 8ET

$P H$ W RAYNER, MB, MRCP, senior lecturer in paediatrics of sex hormones, which bring about the physical changes of puberty. The precise explanation for the decrease in hypothalamic sensitivity is unknown, but it is influenced by genetic factors and nutritional state and may be related to the attainment of a critical body weight. There is a secular trend in the onset of puberty: the age at the menarche, for instance, has decreased progressively since records were first kept, and small differences exist between racial groups and social classes. These differences, however, are not significant in clinical practice.

\section{Age at onset and events of normal puberty}

GIRLS

The onset of puberty occurs about 18 months earlier in girls than in boys. The first event is usually breast development, which occurs at the age of 11 , followed by the growth of pubic hair at $11 \frac{1}{2}$ and the menarche at 13 to $13 \frac{1}{2}$. The pubertal growth 